\title{
To study the knowledge and attitude of postnatal mothers on neonatal jaundice in Motahari Hospital, Iran
}

\author{
Soheila Rabiyeepoor ${ }^{1}$, Shahsanam Gheibi ${ }^{2}$, Saeideh Jafari ${ }^{1}$ \\ ${ }^{1}$ Reproductive Health Research Centre, Urmia University of Medical Sciences, Urmia, Iran \\ ${ }^{2}$ Maternal and Childhood Obesity Research Centre, Urmia, Iran
}

\section{Email address:}

Soheila80@yahoo.com (S. Rabiyeepoor),drgheibi@yahoo.com (S. Gheibi), saeideh.jafarie@yahoo.com (S. Jafari)

\section{To cite this article:}

Soheila Rabiyeepoor, Shahsanam Gheibi, Saeideh Jafari. To Study the Knowledge and Attitude of Postnatal Mothers on Neonatal Jaundice in Motahari Hospital, Iran. Clinical Medicine Research. Vol. 3, No. 1, 2014, pp. 1-5. doi: 10.11648/j.cmr.20140301.11

\begin{abstract}
Background: Neonatal jaundice (NNJ) is one of the most common disorders worldwide. In time and proper management to reduce serious neurological complications depends on mothers' knowledge and beliefs about NNJ. Objective: To determine knowledge and attitude on neonatal jaundice of postnatal mothers in Motahari Hospital, Urmia, Iran. Methods: In this descriptive-analytical study, 200 mothers who delivered in Motahari Hospital, Urmia, Iran, were interviewed in the first 3 days of delivery, using a structured questionnaire. Results: The mean knowledge score was 6.65 $(\mathrm{SD}=3.5)$ out of 15 and the mean attitude score was $25.9(\mathrm{SD}=4.48)$ out of 35 . The knowledge of mothers on causes, treatment and complications of neonatal jaundice was not adequate. Knowledge and attitude scores were correlated with the past experiences of neonatal jaundice and educational levels. Conclusion: There are still misconceptions on the risk factors, treatments and complications of neonatal jaundice among mothers. Special educational programs are needed to increase the awareness of mothers.
\end{abstract}

Keywords: Neonatal Jaundice, Knowledge, Attitude, Mothers

\section{Introduction}

Neonatal jaundice (NNJ) is one of the most common and important conditions during the neonatal period. It is estimated to be present in about $60 \%$ of the full term and $80 \%$ of preterm infants $(1,2)$. It refers to the yellow discoloration of the skin and sclera of newborn infants $(3,4)$. In most infants unconjugated hyperbilirubinemia usually leads to a normal provisional event. When it raises immoderately more than $20 \mathrm{mg} / \mathrm{dl}$ in healthy and normal birth weight babies, it is a great concern because unconjugated bilirubin is neurotoxic and can cause lifelong neurologic sequel (kernicterus) and death $(3,5)$. Based on a study, kernicterus has at least $10 \%$ mortality and $70 \%$ morbidity (6). It is incurable, but if jaundice is seized early and effective therapy started soon, kernicterus is preventable (5).

Nowadays, newborns are discharged early from hospitals, therefore mothers play an important role to recognize jaundice and control it properly (7). Any action taken by mothers is influenced by their knowledge and attitude of neonatal jaundice. In order to schedule educational programs in this case, it is essential to estimate mothers ' knowledge and attitude toward neonatal jaundice.

\section{Methods}

This descriptive-analytical study was carried out at Motahari teaching hospital, Urmia, Iran. The study population consisted of 200 postpartum mothers, admitted to obstetric ward, and they were interviewed on the first three days after delivery, before they were discharged.

Data was collected using a structured, pretested, researcher-administered questionnaire. A pilot study was done on 15 mothers, using the same setting and questionnaire to assess the feasibility of the study that revised to remove ambiguities and clarify the questions. Its content validity was assessed by professionals. The Medical Ethics Committee of Urmia University of Medical Sciences confirmed ethical consideration of this study.

Prior to the study, an informed consent was obtained from the responders. Adequate guides on how to answer the questions were given to the mothers. Severe ill mothers, mentally subnormal mothers and mothers who had not given consent for the study were excluded. 
Table 1: Mothers'demographic characteristics $(n=200)$

\begin{tabular}{|c|c|c|}
\hline \multirow{2}{*}{ Characteristic } & \multicolumn{2}{|c|}{ Value } \\
\hline & $\mathbf{N}$ & $\%$ \\
\hline \multicolumn{3}{|l|}{ Age (years) } \\
\hline$<19$ & 24 & 12 \\
\hline 20-34 & 141 & 70.5 \\
\hline$>35$ & 35 & 17.5 \\
\hline \multicolumn{3}{|l|}{ Place of residence } \\
\hline city & 130 & 65 \\
\hline village & 70 & 35 \\
\hline \multicolumn{3}{|l|}{ Occupation } \\
\hline House wives & 159 & 79.5 \\
\hline Clerks and office support & 21 & 10.5 \\
\hline Self employed & 18 & 9 \\
\hline Manual laborer & 2 & 1 \\
\hline \multicolumn{3}{|l|}{ Educational level } \\
\hline No schooling & 36 & 18 \\
\hline Academic education & 63 & 31.5 \\
\hline Elementary education & 44 & 22 \\
\hline High school education & 27 & 13.5 \\
\hline University education & 30 & 15 \\
\hline \multicolumn{3}{|l|}{ Delivery mode } \\
\hline Natural vaginal delivery & 121 & 60.5 \\
\hline Cesarean section & 79 & 39.5 \\
\hline \multicolumn{3}{|l|}{ Birth order } \\
\hline 1 & 72 & 36 \\
\hline$\geq 2$ & 128 & 64 \\
\hline
\end{tabular}

The questionnaire consisted of 31 questions in 4 sections. First part contained sociodemographic data of the mothers, second part was about the health care instruction. Afterwards, 15 close ended questions, totally 15 scores, were used to assess the respondents' knowledge on neonatal jaundice, which were graded as correct and incorrect. The total score of the correct answers of knowledge questions were used to categorize respondents as: poor knowledge (0-5), moderate knowledge (6-10) and good knowledge (11-15). To assess the respondents' attitude about how to manage the neonatal jaundice, 7 questions were rated according to a five-point likert scale (strongly agree/ agree/don't have any idea/disagree/strongly disagree). The attitude scores were graded to: poor attitude (0-12), moderate attitude (13-24) and good attitude (25-35). The data was analyzed descriptively using SPSS software version 21.

\section{Results and Discussion}

The mean age of the mothers participated in this study was $27.10(\mathrm{SD}=6.9)$ years old; which $12 \%$ were less than 19 (the youngest were two 13 years old women), $70.5 \%$ were $20-34$ and $17.5 \%$ more than 35 . City residents were $65 \%$ and the rest were from villages. About their occupation, $79.5 \%(n=159)$ were housewives, of which $8.8 \%$ $(n=14)$ were university students. Of all, $10.5 \%$ were clerks, $9 \%$ of the mothers were occupied on their own business and $1 \%$ was laborer. Illiterate mothers were $18 \% \quad(n=36)$ while $31.5 \%(n=63)$ and $22 \%(n=44)$, respectively, had academic and elementary educations, $13.5 \%(n=27)$ had high school education and $15 \%(n=30)$ had experienced university. Natural vaginal delivery rate was 121 and 79 had cesarean section. Of neonates, 72 (36\%) were first birth rank, and the remaining 128 (64\%) were second and more.

Of all 200 respondents, 46 mothers had a past history of their children developing neonatal jaundice. Only 21 $(45.6 \%)$ of the latter group $(n=46)$ were educated about $\mathrm{NNJ}$ in their previous affected infants and 54.3\% were not; despite having affected baby. Of the other 154 mothers, 103 $(66.8 \%)$ had neither experienced NNJ, nor informed about that. Remaining $51(33.1 \%)$ of whom had not experienceda jaundiced neonate, had gotten some kind of information about NNJ with the source of books, magazines, mass media, doctors, antenatal talks and also relatives and neighbors. About the necessity of educating mothers on NNJ, 88.5\% $(n=177)$ of responders agreed that mothers should be educated on NNJ. Of the remaining 23 mothers, $65.2 \%(n=15)$ had no idea and others disagreed. About the most effective method to educate mothers, $6 \%$ of the mothers didn't have any idea on any method, and others preferred one-to-one counseling by the doctors, regular antenatal talks and TV programs, articles in magazines and newspapers and radio programs, respectively. Generally, concerning NNJ as a very important problem, most of the mothers mentioned that mothers must be informed and educated about it. It must be taught at schools and universities and is good to prepare written leaflets and distribute them to families.

Table 2: Mothers experience and view of education on neonatal jaundice

\begin{tabular}{llc}
\multicolumn{1}{c}{ Experience/education } & \multicolumn{3}{c}{ Total number } \\
& N & \% \\
\hline who had experienced jaundiced neonate in the past & 46 & 23 \\
Had informed about NNJ & 77 & 38.5 \\
& & \\
Agreed with educating mothers on NNJ & 177 & 88.5 \\
The most effective method to educate mothers on & & \\
NNJ according to the respondents' ideas & & \\
One-to-one counseling by doctors & 99 & 49.5 \\
Antenatal talks by health providers & 92 & 46 \\
Regular programs in television & 83 & 41.5 \\
Articles in magazines & 22 & 11 \\
Regular newspaper articles & 12 & \\
Regular talks in radio programs & 84 & \\
Educational programs in school & 63 & \\
Others & 94.5 \\
Don't know & 126 & \\
\hline
\end{tabular}

The mean knowledge score was $6.65(\mathrm{SD}=3.5)$ with the range of 0 to 15 . In this study $50 \%$ of mothers got the moderate score in knowledgement section while $36.5 \%$ were in low-knowledge group. These results were significantly higher than the study in Sari, Iran(8).Majority 
of mothers (90\%) correctly defined NNJ as a yellow discoloration of newborns skin. It is similar to a study in Malaysia and is much better than some other studies $(2,3,9)$. Of the remaining, $2 \%$ were only aware of a condition in newborns named NNJ and nothing more and $8 \%$ had not ever heard about NNJ. This was $30 \%$ in a study in Nigeria (9). In this study, $45.5 \%$ of mothers were not aware that jaundice in new born is a common problem. More than $60 \%$ of mothers affirmed jaundice lasting more than 2 weeks is not abnormal. They said it was like having a cold; it might last 2 or 3 weeks. Large number of them $(75 \%)$ was not aware that NNJ of early onset was abnormal and needed urgent treatment. They believed that normally NNJ appears at the first hours of birth; if not, the baby will never be affected. In a study, Malaysian mothers were more knowledgeable about these facts than the mothers in this $\operatorname{study}(3)$.

About $80 \%$ in this study did not agree breast feeding can cause jaundice in neonates. They noted it was the best food for newborns and was impossible to cause illness. Almost $70 \%$ believed that certain foods especially yellow color foods like snacks, turmeric, yellow drinks taken by the breast feeding mothers cause jaundice in their infant. These misconceptions were similar to another study in $\operatorname{Iran}(7)$. Their sources of information were their friends, neighbors or relatives who might have also gotten wrong information.

About the factors that increase the risk of NNJ, 37\% of the mothers stated infection in newborn and $48 \%$ knew prematurity as a risk factor for NNJ. It was $7.1 \%$ in a study in Nigeria and of course none of the participants knew that in Sri Lanka $(2,9)$. As a cause of NNJ, more than $70 \%$ of the mothers were not aware that differences in fetalmaternal blood groups cause jaundice. They mentioned the fetus was alive with its mother's blood; how this blood could be harmful. Of course $28.5 \%$ answered it correctly and it is comparable to Nigerians mothers in a study (9). In another study in Iran risk factors for hyperbilirubinemia were $\mathrm{ABO}$ incompatibility, prematurity and infection, respectively (10). It is observed in this study that a small group of mothers knew these important risk factors.

About $30 \%$ of respondents didn't know phototherapy as a treatment of NNJ. Although some of them said jaundiced baby must be kept in a special device, they didn't know that was phototherapy. Some mothers didn't know how to treat NNJ, at all. Similar to some other studies, the present study revealed that placing a jaundiced infant at the exposure of sunlight was common and many of them were not aware that it can increase the risk of dehydration and worsen the severity of jaundice (11-13). They declared the sun rays were very useful and a good treatment for NNJ. Of course $24 \%$ emphasized special rays were needed for the phototherapy and the sun could have harmful effects. These misconceptions lead to a long delay after jaundice appears and before the first visit of a doctor and may cause some side effects on the baby.

Regarding the sequel of NNJ, $46.5 \%$ and $56 \%$ of the mothers, respectively, knew severe jaundice could cause death and brain damage. But only $28 \%$ knew that hearing impairment could be a result of that. Unfortunately, just 35 (17.5\%) mothers knew all 3 complications and 34.5\% $(n=65)$ didn't know any of them. These are statically lower than mother's knowledge of complications in a study in Malaysia (3). Knowledge of mothers about neonatal death as a complication of $\mathrm{NNJ}$ is similar to some previous studies and is pretty higher than in Nigerians $(2,7,9)$.

The level of attitude about NNJ was satisfying. Mean attitude score was 25.92 ( $\mathrm{SD}=4.84$ ) with the range of 14 to 35 . Of all the responders, $37 \%$ and $63 \%$, respectively, belonged to moderate and high attitude categories and no one had low attitude. It is obvious that most postnatal mothers had correct attitude on NNJ.

Table 3: Knowledge of mothers on neonatal jaundice

\begin{tabular}{|c|c|c|}
\hline \multirow{2}{*}{ Questions of knowledge on neonatal jaundice } & Correct answers & \multirow{2}{*}{$\begin{array}{l}\text { Incorrect answers } \\
N \%\end{array}$} \\
\hline & $N \quad \%$ & \\
\hline It is a condition characterized by the yellow discoloration of the skin of newborns & 18090 & 2010 \\
\hline It is a common problem in newborns & 54.5 & 9145.5 \\
\hline Lasting jaundice more than 2 weeks in a newborn is abnormal & 39 & 12261 \\
\hline Appearing jaundice during the first 36 hours is abnormal & 50 & 150 \\
\hline A reason for neonatal jaundice is breast milking & 19.5 & 16180.5 \\
\hline Prematurity is a risk factor for neonatal jaundice & 9648 & 104 \\
\hline A treatment for neonatal jaundice is phototherapy & 13969.5 & 30.5 \\
\hline Infection higher the risk of neonatal jaundice & 74 & 126 \\
\hline Food taken by the breast feeding mothers can cause jaundice in their infants & 66 & 134 \\
\hline Severe jaundice may cause death in neonates & 9346.5 & 53.5 \\
\hline Severe jaundice may cause brain damage in neonates & 112 & $88 \quad 44$ \\
\hline Severe jaundice may cause hearing loss in neonates & 56 & 14472 \\
\hline Jaundiced infants may need to have several blood testing by medical personnel & 13366.5 & 6733.5 \\
\hline $\begin{array}{l}\text { Exposure of a jaundiced infant to the sun will increase the risk of dehydration and worsen the } \\
\text { condition }\end{array}$ & $48 \quad 24$ & 152 \\
\hline Differences between fetal-maternal blood groups higher the risk of neonatal jaundice & 5728.5 & 71.5 \\
\hline
\end{tabular}


On the question of whether they considered NNJ a serious problem or not, since some mothers didn't have adequate knowledge about the condition and complications, $14.5 \%$ answered 'no' and $27.5 \%$ didn't have any idea about that. In Nigeria affirmative answers to this question were more than current study (9).

We were glad that $80 \%$ of the responders agreed consulting physicians if jaundice develops, and hospitalizing their neonates if necessary. But 3.5\% of them didn't agree with hospitalization of their baby and $16.5 \%$ said there was no need to hospitalize the baby because it was not so serious and would be cured at home as well. A total of $63 \%$ mothers agreed for several blood testing of their baby and they noted the best choice as soon as jaundice develops in a baby was referring to physicians and let them do what was needed. Of all responders, $32 \%$ doubted that such a harmful disease was completely curable. They mentioned for infants were very weak, it was a big worrisome if jaundice would be cured forever. In a Study in Iran almost all knew that NNJ wascurable (7).

This study demonstrates that traditional beliefs such as glucose water, bathing with gold, put a piece of gold in his bed and dressing baby red are still accepted by thepeople. Some mothers said they would consult physicians as well as using traditional treatments, and they didn't know which was better; however some said traditional treatments were better and more effective.

Table 4: Attitude of mothers about neonatal jaundice

\begin{tabular}{|c|c|c|c|c|c|c|c|c|c|}
\hline \multirow{2}{*}{$\begin{array}{l}\text { Attitude questions on neonatal jaundice } \\
\text { I am worried about developing jaundice in my infant }\end{array}$} & \multicolumn{2}{|c|}{$\begin{array}{l}\text { Completely } \\
\text { agree } \\
N \% \\
\end{array}$} & \multicolumn{2}{|c|}{$\begin{array}{l}\text { Agree } \\
\text { N\% }\end{array}$} & $\begin{array}{l}\text { No idea } \\
N \%\end{array}$ & \multicolumn{2}{|c|}{ Disagree } & \multicolumn{2}{|c|}{$\begin{array}{l}\text { Completely } \\
\text { disagree } \\
N \quad \%\end{array}$} \\
\hline & 24 & 12 & 91 & 45.5 & $66 \quad 33$ & 17 & 8.5 & 2 & 1 \\
\hline $\begin{array}{l}\text { I am worried about several blood testing of my infant } \\
\text { because it can cause anemia }\end{array}$ & 4 & 2 & 23 & 11.5 & 4723.5 & 97 & 48.5 & 29 & 14.5 \\
\hline $\begin{array}{l}\text { If jaundice develops in my infant, I will use traditional } \\
\text { treatment because this disease is not dangerous }\end{array}$ & 2 & 1 & 28 & 14 & 3517.5 & & 42.5 & 50 & 25 \\
\hline $\begin{array}{l}\text { If jaundice develops in my infant, I won't use traditional } \\
\text { treatment because it may be harmful for him }\end{array}$ & 472 & & 70 & 35 & 2010 & 54 & 27 & 94 & 4.5 \\
\hline $\begin{array}{l}\text { If jaundice develops, since I am afraid of hospitalizing my } \\
\text { infant, Iwon't consult a physician }\end{array}$ & 2 & 1 & 5 & 2.5 & 3316.5 & 90 & 45 & 703 & \\
\hline Neonatal jaundice is a serious condition & 37 & 18.5 & 793 & & 5527.5 & 26 & 13 & 3 & 1.5 \\
\hline $\begin{array}{l}\text { Early referring to physician and getting proper treatment, } \\
\text { neonatal jaundice is curable }\end{array}$ & 271 & & 109 & 54.5 & $\begin{array}{ll}57 \quad 28.5\end{array}$ & 5 & 2.5 & 2 & 1 \\
\hline
\end{tabular}

\section{Conclusion}

The highest knowledge and attitude scores were obtained by mothers who had previously experienced jaundiced babies and who had educated about that, before. It is obvious that informing mothers will give good results and reduces many harmful effects.

Mothers living in cities were somehow more knowledgeable than village residents; however there were not significant differences between their attitudes. There were statistically low scores in illiterate and primary school categories compared to higher educated groups. But there were no significant differences among other educational groups.

In conclusion, the findings of the present study show that there is a need for increasing the awareness of mothers on all aspects of neonatal jaundice such as causes, side effects and emergent reference to doctors, to prevent irreversible complications. To improve the level of awareness and attitude, educational purposes must be programmed for the problem.

In view of the different education levels and cultural and traditional beliefs, these factors should be taken into consideration during the design of educational methods and materials.

Antenatal talks and regular TV programs can help to educate alarge number of mothers. As well informing school and university students can be so helpful.

Table 5: Relationship between age groups and mean knowledge and attitude

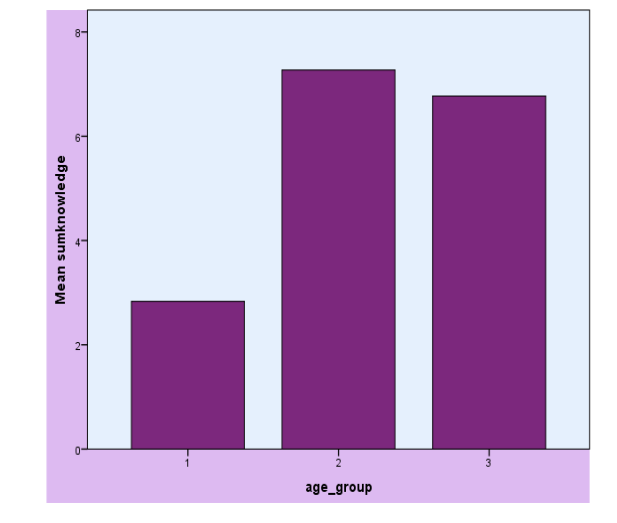

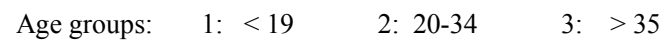




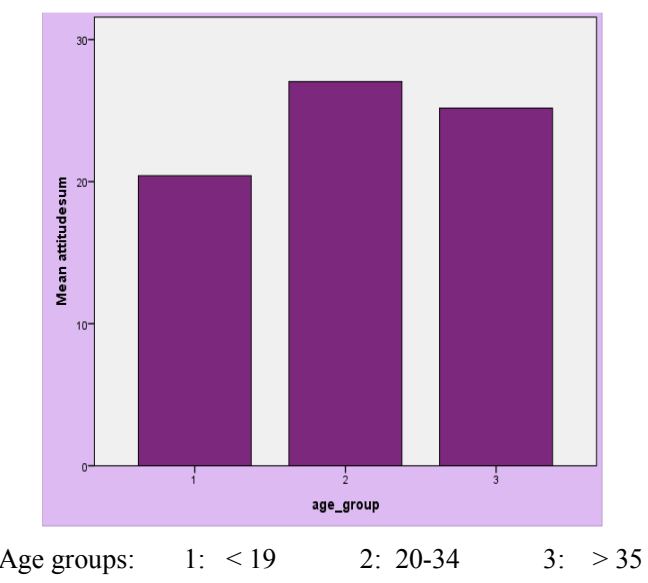

\section{Acknowledgement}

This article was extracted from the final thesis of Saeideh Jafari which was conducted with the collaboration of Ghaffari S. and Urmia Reproductive Health Research Center and Maternal and Childhood Obesity Research Center. We are thankful to the postpartum mothers who participated in this study.

\section{References}

[1] C. Omar, S. Hamza, A. Me. Bassem, R. Mariam, North American Journal Of Medical Sciences, 2011, 3, 12, 544547
[2] B. K. N. R. Rodrigo, G. Cooray, Sri Lanka Journal of Child Health, 2011, 40, 4, 164-168

[3] N. Y. Boo, FRCP, C. Y. Gan, Y. W. Gian, K. S. L. Lim, M. W. Lim, H. Krishna-Kumar, MRCOG, Med J Malaysia, 2011, $66,3,239-243$

[4] M. Dash, Research and Review: Journal of Medical and Health Sciences, 2013, 2, 3, 41-46

[5] B. A. Egube, A. N. Ofili, A. R. Isara, J. U. Onakewhor, Nigerian Journal of Clinical Practice, 2013, 16, 2, 188-194

[6] S. Ip, M. Chung, J. Kuling, R. O’Brien, R. Sege, S. Glicken, M. J. Maisels, J. Lau, Official Journal of the Americam Academy of Pediatrics, 2004, 114, 1, 130-153

[7] N. Khalesi, F. Rakhshani, Journal of Pakistan Medical Association, 2008, 58, 12, 671-674

[8] V. Ghaffari, K. Vahidshahi, B. Taleshi, Mazandaran University Medical Journal, 1385, 16, 52, $92-99$

[9] A. U. Eneh, R. O. Ugwu, Nigerian Journal of Clinical Practice, 2009, 12, 2, 187-191

[10] F. Zarrikoub, A. Beigi, Tehran University Medical Journal, 2007, 65, 6, 54-59

[11] F. Dehghani, S. Mohammadalizadeh, M. Kazemian, Gilan University Medical Journal, 1380, 10, 37-38, 42-47

[12] P. C. Sheidt, E. D. Mellits, J. B. Hardy, J. S. Drage, T. R. Boggs, J. Pediatr, 1977, 91, 2, 292-297

[13] W. B. Poon, W. L. C. Ho, C. L. Yeo, Singapore Med J, 2007, $48,11,1006-1011$ 